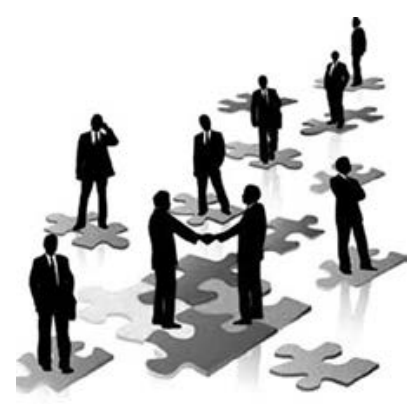

Удк 314/316:004

DOI 10.20339/AM.05-20.097

\section{ОБЩЕСТВО. НАУКА. ОБРАЗОВАНИЕ}

\section{С.А. Ветров,}

д-р филос. наук, проф., заведующий кафедрой «Связи с общественностью, сервис и туризм»

Д.В. Конишевский, канд. филос. наук, доц. Омский государственный университет путей сообщения e-mail:dv_konishevsky@mail.ru

\title{
ЦИФРОВОЙ МЕЙНСТРИМ
}

Исследована тема цифровизации как глобального тренда современного социокультурного развития, которая нуждается в детальном осмыслении и анализе, т.к. помимо очевидных положительных аспектов, данный феномен включает ряд проблем, являющихся причиной негативных перспектив для будущего всего человечества. Изучение этих проблем поможет осознать феномен цифрового мейнстрима и выстроить механизм социокультурного проектирования, исключая серьезные потрясения.

Ключевые слова: иифра, цифровой человек, цифровой мейнстрим, цифровизация, прекариат, презентизм, цифровой мир, цифровой капитализм.

\section{DIGITAL MAINSTREAM}

S.A. Vetrov is Dr.Sci. (Philosophy), prof. head of sub-faculty; and D.V. Konishevsky is Cand.Sci. (Philosophy), doc. at Omsk State Transport University

Researched is the theme of digitalization as a global trend in modern sociocultural development, that needs detailed understanding and analysis, since in addition to the obvious positive aspects this phenomenon includes a number of problems, that cause negative prospects for the future of all mankind. Studying these problems will help to understand the phenomenon of the digital mainstream and form a mechanism for sociocultural design, eliminating serious shocks.

Key words: digit, digital person, digital mainstream, digitalization, precariat, presentism, digital world, digital capitalism

\section{Феномен цифровизации и цифровой человек}

Характеризуя растущее значение цифровыхтехнологий в жизни современного социума, можно со всей определенностью использовать понятие мейнстрим. Цифровизация стала не просто технологическим новшеством, но приобрела вид популярной тенденции, активно обыгрываемой массовой культурой. «Цифра» становится полноценным воплощением актуальных «трендов»:

- изменения характера занятости (фриланс);

- расширения слоя прекариев ${ }^{1}$;

- развития цифрового маркетинга;

- увеличения доли «цифры» в сфере досуга;

\footnotetext{
${ }^{1}$ Термин «прекарий» попал в оборот с легкой руки социолога Гая Стендинга, автора бестселлера «Прекариат: новый опасный класс». Прекарий - новый социальный слой людей, лишившихся стабильной перспективы обеспеченности. - Примеч. ред.
}

- проникновения «цифры» в систему административного управления и др.

Цифровой мейнстрим набрал обороты не только по причине перспективности новых технологий, но и потому, что «цифра» стала основой богатства и успеха целого ряда новаторов и творцов: М. Цукерберга (Facebook), Дж. Безоса (Amazon), Б. Гейтса (Microsoft), С. Брина и Л. Пейджа (Google), К. Систрома (Instagram), Я. Кума (WhatsApp), П. Дурова (Telegram). Они, подобно Ф. Кортесу, подчинившего империю ацтеков с ее несметными богатствами, подарили огромному числу людей мечту о цифровом Эльдорадо. Блогеры, IT-специалисты, интернет-маркетологи, музыканты, шоумены устремились за подписками, комментариями и лайками. Никто не ищет смысла, все ловят «хайп».

«Цифра» во всех ее видах обрела широчайшую популярность. На данный момент цифровой мейнстрим и не соби- 
рается угасать. Напротив, он захватывает все новые области. Явление, именуемое «хайпом», может сопровождать любое событие, которое сразу начинает претендовать на значимость. Складывается нравственно-ценностная парадигма, характеризующаяся отказом от метанарраций, вследствие чего трансформируются традиционные аксиологические установки.

В современной России к цифровому мейнстримному движению можно отнести создание сетевых сообществ самого разного направления, формирование сетевого сленга и сетевого инструментария, увлечение криптовалютой и игрой на валютных биржах, интернет поддержка (подписки, сбор финансов) оппозиционных политиков. Все это и многое другое сливается в цифровой поток, который часто подменяет реальность. Можно утверждать, что цифра оформилась в квазикультуру, которая строится на ощущении кризиса от утраты метанарраций. Складывается своеобразная социокультурная альтернатива настоящему варианту традиционности. Она обретает вид актуального состояния общества, главным постулатом которого является отсутствие целостности и отторжение любой попытки ее создания.

Цифровым «жрецам» удается корректировать поведение пользователей, выделять новые тренды, придавать им статус мейнстримных. Пользователи стремятся подписываться на модных блогеров и чувствовать себя причастными к значимым событиям (массовая истерия по поводу флешмоба в поддержку О. Сенцова «Свободу Сенцову»). Модным становится участие в интернет-благотворительности (помощь больным детям, брошенным животным), набирают популярность обучающие программы. Все более актуальной цифровая площадка становится для реализации хобби. А обладание флагманским смартфоном позволяет позиционировать себя как суперуспешного и сверхудачливого индивида.

«Цифра» обретает субъектность. Она определяет, направляет, корректирует. Общество, пока в виде корпоративных объединений, государственных учреждений, структур административного управления, стремясь быть в тренде, пытаясь угадать логику цифровых нововведений, забегает вперед и создает различные варианты самоорганизации и самоконтроля, подчас не облегчая, а усложняя себе жизнь. Реализуется классический вариант отчуждения. Результат человеческой деятельности обрел самостоятельную жизнь и влияет как на человека, так и на общество в целом.

Следующий этап - безусловное доминирование искусственного интеллекта. В повестке дня сегодня - этическая сторона этого этапа, выраженная в принципах взаимодействия человека и искусственного интеллекта как ответ на рост интереса к новым технологиям, которые могут таить опасность при недобросовестном пользовании [1].

Складывается впечатление, что «цифра» уловила суть мейнстримного движения. Она лучше всего помогает ка- заться, а не быть. В обществе, где главным предпочтением является успех, незаменимой становится иллюзия бытия.

Полагаем, что цифровой мейнстрим будет только набирать обороты. «Футуризм XX в. заменен хаотичной культурой «настоящего момента» XXI в. Из футуристов мы все превратились в презентистов» [2.С. 9].Д. Рашкофф подобное состояние обозначает как «коллапс нарратива». Развивается неспособность к последовательному изложению. Утрата стремления к целостности заменяется спокойной уверенностью в том, что целостность есть. Сегодня нет необходимости в стремлении ее постигнуть посредством постоянного интеллектуального труда. Цифровой человек отказывается от духовного самосовершенствования. Его занимают лишь новые варианты и новые приспособления подключения к цифровой реальности. В данном состоянии есть что-то религиозное, поскольку подключение приобретает вариант причащения (квазипричащения, конечно). Смыслом наделяется не реальность, но лишь гиперподключенный мир. Главной ценностью становится способность ориентироваться в сетевом обществе.

«Презентизм - представление о том, что существуют только вещи или явления, пребывающие в настоящем. Согласно презентизму, нет только будущих или только прошлых вещей и явлений» [3. С. 178]. Идет нарастающее разрушение ретроспективного взгляда на жизнь. Формируется парадоксальная ситуация, когда современники ужасаются прошлому («сталинский режим»), но, очертя голову, бездумно готовы рвануть в будущее по принципу «потом видно будет». Происходит деформация фундаментальных институтов. Семью вытесняет киберсекс, дружбу сетевые клубы, государство противопоставляется обществу, культивируется модель безответственной, сопровождаемой хайпом оппозиционности. Сущность уступает самому примитивному варианту формы - оболочке.

Цифровой мир создает новый тип человека, который охотно фиксирует каждый момент своей жизни. Мировоззрение презентизма культивирует единственно возможную модель поведения в пределах торжествующей сиюминутности - непрекращающейся самопрезентации. Цифровой человек приучен формирующимся утилитаристским миром не просто фиксировать, а делать предметом для всеобщего обозрения акты еды, отдыха, работы, вождения автомобиля, даже соития с другим человеком. Все поведение такого индивида словно призывает: алгоритмизируй меня.

Новый социальный порядок, новый человек живут исключительно чувственным настоящим. Из духовных предпочтений лишь бесконечная жажда новых впечатлений, эмоций, которые, кстати, так же материализуются и физиологизируются. Данные впечатления описываются словами: увидел, попробовал, почувствовал прилив адреналина и др. Иными словами, эти эмоции можно просчитать, упаковать и продать. В этом случае жизнь человека и сам человек монетизируются. «Горькая ирония состоит в том, что чем точнее интернет 
фиксирует все, тем более атрофируется наша память. В результате возникает амнезия на все, кроме немедленного, мгновенного, сиюминутного и моего. Это и есть конец истории как разделенной общей памяти, конец нашей коллективной взаимосвязанности с прошлым и будущим» [3. С. 178].

Неконтролируемая цифровизация, осуществляемая либертариански ориентированными корпорациями, расчищает пространство для мировоззрения, которое строится на вседозволенности, сознательном попрании нравственных принципов. Мятежность, бунтарство, ниспровержение основополагающих институциональных норм, правил преподносится как естественная очевидность.

Культура также обрела черты мейнстрима. Обычным становится презрение к государству. Культивируется идея свободного интернета как основы демократии, полноценной самореализации и финансового благополучия. Однако такая позиция служит идеологическим прикрытием для политики монополизации со стороны таких мощных корпораций, как Uber, Apple, Google, Facebook, Amazon, YouTube, а в России Сбербанк и др.

Безграничная свобода оборачивается сокращением рабочих мест, жестким контролем над пользователями, увеличением пропасти между богатыми и бедными. А молодые и креативные, пытающиеся разбогатеть в цифровой реальности, напоминают свободных старателей или вольных нефтедобытчиков в период золотой или нефтяной лихорадки. Участь их известна. Главный приз все равно получат корпорации. Опасность описываемой ситуации заключается в незаметной подмене позиции «мысли нестандартно» позицией «мысли безответственно».

Цифровой капитализм создает модель, независимую от социальных обязательств под лозунгом освобождения от архаичного, мешающего развитию института посредничества. По мнению адептов цифрового капитализма, интернет стал площадкой, свободной от трения норм, регламентов, а помимо того и от социальных отчислений и налогов для общения продавцов и покупателей. Однако такая свобода легко воплощается в циничных действиях. Так, например Uber, вслед за посредниками между покупателем услуг и собственной транспортной сетью устраняет профсоюз как посредника между работниками и руководством компании. При этом Uber без колебания повышает тариф на 700-800\% за проезд в случае ухудшения погодных условий.

Либертарианская установка на приватизацию частными компаниями государства ложится в основу антигосударственной стратегии. Гражданам внушается мысль о неповоротливости и излишней забюрократизированности государственных институтов и их неспособности служить интересам простых людей. Формируется мнение, что цифровизация обеспечит приближение государства к гражданам. Под разглагольствования о социально ориентированном государстве проводит- ся популяризация политики передачи социальных функций крупным корпорациям.

Ш. Пешавар предложил откровенную и циничную формулу. «Давайте просто «таскребитируем» и «уберизируем» правительство» [4]. Это приводит лишь к изменению проблемного поля, а не к устранению его. Вместо сглаживания социальных противоречий между населением и властью формируется новое, обусловленное цифрой расслоение общества. Мы можем стать свидетелями воплощения своеобразных проектов, утопических (для элиты) или антиутопических (для простого населения). Своеобразные летающие острова (Лапута Дж. Свифта) или орбитальные станции повышенной комфортности (Элизиум Н. Бломкампа), либо вполне земные по природе, но фантастические по комфорту территории существования цифровой элиты. В любом случае эти анклавы власти и комфорта уподобляются средневековому замку. Построена хай-тек версия феодального мира.

Демократические идеалы отброшены, людей развели в два измерения. Складывается новая структура неравенства. Ее характерная черта, в отличие от предыдущих типов социального расслоения, заключается в том, что и элита и население пользуются одним видом благ, но качественно несопоставимых. Есть авиаперелеты корпоративных компаний и авиаперелеты лоукост, вино, табак, еда в одних и тех же упаковках, но отличающиеся по качеству, отдых на море в эксклюзивных местах и в плебейских резервациях организованных по принципу «все включено», есть элитное, строящееся практически на индивидуальном обучении образование и «демократические» онлайн курсы, которые могут легко перерасти в онлайн вузы с онлайн дипломами. Новая реальность создает очередной вариант стратификации общества и позволяет держать всех под контролем и управлять питанием, досугом, лечением, обучением посредством упаковки, этикетки, товарного знака, бренда и др.

«Как и во времена Средневековья, Google, Apple и Facebook отделяются от физической реальности нищающих вокруг них городских сообществ. Мало того, предоставляя изобилие бесплатных услуг для своих сотрудников, эти компании разрушают местный малый бизнес, который традиционно занимался обслуживанием офисных сотрудников» [3.С. 173]. Сложились новая архитектура, дизайн, корпоративный стиль, клубный досуг и др. Корпорациям «лабораторным» способом удалось вывести новый антропологический тип сотрудников с цифровым мировоззрением, которое направлено исключительно на результат. Причем, виртуализированный результат, предполагающий исключительно финансовое выражение.

«Интернет-компании, подобные Google, Apple, Facebook или Twitter, уже объявили свою независимость архитектурным и любым иным образом от мира вокруг них. Цифровые властители отделились от аналоговых крестьян. Это окончательный исход» [3. С. 173]. Превратив в общепринятые, 
практически приобретшие статус банальных идеи свободы, занятость вне фиксированного места работы, ценности самостоятельного определения трудового графика, интернет корпорациям удалось сформировать и широко распространить идеологию приемлемости частичной занятости.

Разработаны многочисленные варианты цифрового оброка, сложился новый класс работников, который Г. Стэндинг обозначил как прекариат. Прекариев в условиях новых технологий можно квалифицировать как современный вариант поденщиков. Впрочем, сегодня специалисты по управлению человеческим капиталом придумали много благородных по произношению обозначений для неуважаемых в системе неолиберальных ценностей профессий: не поденщик, а фрилансер, не уборщица, а клиринг-менеджер, не секретарь-машинистка, а офис-менеджер и др.

Однако как ни называй новый класс работников, им предлагается только один вариант существования. Это постоянный поиск разового заработка и, следовательно, тотальная зависимость от работодателя, обильно сопровождаемая разглагольствованиями о свободе выбора и творчества. Нас настойчиво вталкивают в ситуацию, «когда найти сдельную разовую работу проще, чем долгосрочную», и «эта крайне ненадежная модель занятости, обратная темная сторона капитализма в духе «сделай сам» становится все более важной частью новой сетевой экономики» [3. С. 158].

Создаются модели распределенной рабочей силы. Одна из таких моделей - TaskRabbit, которая предполагает кратковременный контракт под конкретный проект без полноценных социальных обязательств со стороны работодателя. Подобный вид деятельности вынуждает работать не «от звонка до звонка», как на заводе или в учреждении, а от момента заключения контракта до полного выполнения работы. Такой вид деятельности полностью истощает физически, психологически и морально.

«Этот революционный проект, созданный за счет преимуществ Кремниевой долины, на самом деле не связан с технологическими инновациями. Это всего лишь очередной шаг в рамках продолжающейся десятилетиями тенденции к фрагментации рабочих мест, изолированию работников и снижению заработной платы» [5].

Проблема цифровизации заключается не только и не столько в изменении технологических реалий современности, сколько в социальных вызовах, детерминированных новыми технологиями. Современные технологические трансформации принципиально меняют саму сущность человека, человеческого и человечности. Человек перестает восприниматься творением Божиим, венцом природы. Он становится куском органического вещества, который после физического истощения может быть элементарно разобран на части.

В набравшем силу процессе цифровизации следует определить его субъекта. При этом необходимо не просто опреде- лить творцов новых способов и принципов технологической цифровизации, ибо этого недостаточно. Творцов «нового дивного мира» необходимо наделить комплексом нравственных обязательств. Понятно, что все либертарианцы цукерберги, грефы, каланики, систромы и др. разгулялись и распоясались, поскольку ошарашили общество своими новациями, красивыми картинками будущей жизни. При этом они не забывают деформировать устоявшиеся институты самозащиты граждан.

Технологические новации, идеи тотальной свободы отнюдь не входят в противоречие с их последовательной, в духе XIX в. политикой удушения структур, препятствующих эксплуатации (профсоюзы, трудовое и социальное законодательство). Отсюда следует вывод, что все эти демиурги должны быть нагружены, как ослы, всей полнотой моральной ответственности перед обществом.

Для решения поставленной задачи необходимо, прежде всего, формировать субъект (активную часть общества) которая:

- осознает весь комплекс проблем, вызываемых новыми технологиями;

- сможет сформулировать и популяризировать сумму претензий, моральных обязательств своих и либертарианской элиты;

- предложить механизмы воздействия, пока морального, на новые центры власти, актуализируя весь потенциал имеющихся под рукой социальных институтов.

В конечном итоге данный субъект осознает всю пагубность в принадлежности «цифре». «Цифра» - всего лишь инструмент, подобный паровому двигателю.

Борьба с «новым дивным миром» предполагает наполнение качественно новым содержанием традиционных институтов, прежде всего государства. Только государство в силах осуществить ряд необходимых мероприятий. К примеру, разбить интернет-корпорации на отдельные компании. Провести жесткие антимонопольные расследования. Наложить огромные штрафы за нарушение неприкосновенности личности. Поддержать правом обязательные запросы пользователей интернета для получение разрешения на создание индивидуального профиля. Законодательно закрепить запрет на покупки в интернет-магазинах несовершеннолетних без согласия их родителей. Поддержать работников интернет-компаний в их стремлении к организации профсоюзов, обеспечению лучших условий труда. Наконец, при помощи законов сделать деятельность интернет-компаний максимально прозрачной.

\section{Заключение}

Подводя общий итог сказанному, отметим, что осуществление вышеперечисленных мер станет первым шагом в перенаправлении цифрового мейнстрима. Человек, формирующийся в процессе решения указанных задач, вернет себе субъектность. 


\section{Литература / References}

1. Ватикан разработал свод этических принципов для искусственного интеллекта. URL: https://echo.msk.ru/news/2596574-echo.html

Vatican elaborates codex of ethical principles for artificial intellect.

2. Rushcoff, D. Present Shock: When Everything Happens Now. New York, 2014

3. Кин Э. Ничего личного: Как социальные сети, поисковые системы и спецслужбы используют наши персональные данные. М., 2016.
Kin, E. Nothing personal: How social networks, search systems and special services use our personal data. Moscow, 2016.

4. This Asshole Misses the Shutdown. URL: http://valleywag.gawker. com/this-asshole-misses-the-shutdown-1447331354

5. Silicon Valley's gig economy is not the future of work - it's driving down wages. URL: https://www.theguardian.com/commentisfree/2014/ jul/23/gig-economy-silicon-valley-taskrabbit-workers

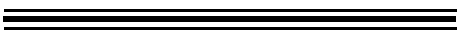

И.А. Евтеев,

канд. культурологии, доц.

Уральский государственный университет путей сообщения e-mail: evteev.cultura@gmail.com

\section{ТЕРРОРИЗМ КАК СОЦИАЛЬНО-КУЛЬТУРНОЕ ЯВЛЕНИЕ}

Представлено авторское аналитическое исследование по изучению и выявлению истоков современного терроризма как социальнокультурного и политического явления. Выявляются взаимосвязи терроризма и общественного мышления, рассматриваются те недостатки личностного строя современного человека, которые делают его безвольным и пассивным объектом устрашения и навязывания террористами своих правил поведения и устоев. Дана оценка терроризма как одного из негативных факторов общего кризиса культуры.

Ключевые слова: террор, терроризм, культура, общество, общественное мышление, социальная регуляция, культурный кризис, государство.

\section{TERRORISM AS SOCIAL CULTURAL PHENOMENON}

I.A. Evteev is Cand.Sci. (Cultorology), doc. at Ural State University of Transport Communications

Presented is the author's analytical research in study and identifying origins of modern terrorism as socio-cultural and political phenomenon Identified is relationship of terrorism with public thinking, and also considered are shortcomings of personal structure of contemporary individual, that make him weak-willed and passive object against intimidation and imposition by terrorists their rules and principles. Given is evaluation of terrorism as one of negative factors of general crisis of culture.

Key words: terror, terrorism, culture, society, social intellection, social regulation, cultural crisis, state.

П роблема терроризма в современную эпоху актуальна по следующей причине. Данное явление претерпело значительную структурно-сущностную трансформацию и намного расширило и усложнило методы своего воздействия на людей, на их сознание. Терроризм сегодня выходит далеко за рамки криминально-боевого устрашения и подавления населения с целью воздействия на власть. Это явление стало весьма своеобразным продуктом нашей эпохи и обратной, изнаночной стороной политического идеала современности - демократии и либерализма.

В наиболее точном определении терроризм суть метод достижения политических или социальных целей, связанный с применением физического и морального насилия, имеющий демонстративный характер и нацеленный на общественный резонанс. Министерство обороны США определяет терроризм как предумышленное применение насилия или угрозы насилия для нагнетания страха с намерением принудить к чему-либо или запугать правительства или общество в качестве средства достижения политических, религиозных или идеологических целей.
Однако в настоящее время террор и терроризм имеют уже иную цель - цель не просто насилия и вселения страха ради выполнения каких-то требований, а цель регуляции поведения населения ради пресечения вседозволенности, недопущения разгула анархии, социальной безответственности. Как ни парадоксально звучит, в наше время терроризм выступает в качестве своего рода эрзац-способа организации общественного устройства путем насилия и принуждения, которое, кстати, во многом анонимно. Подтверждают это достаточно значимые факты: хотя бы тот, что именно терроризм явился действенным стимулятором создания многоуровневой современной системы общественной безопасности.

$\mathrm{H}$ ыне террор и терроризм проявляются в самых различных формах. Терроризировать людей можно необязательно вооруженными криминально-боевыми акциями (взрывы, захват заложников, угон транспортных средств, захват масштабных общественных мест и др.). Своеобразный террор осуществляют и СМИ путем циркуляции разно- 